\title{
A Cosmopolitan One Health Issue: Campylobacteriosis
}

Massimo Giangaspero*

Faculty of Veterinary Medicine, University of Teramo, Italy

*Corresponding author: Massimo Giangaspero, DVM, MSc, PhD, Faculty of Veterinary Medicine, University of Teramo, Italy, E-mail: giangasp@gmail.com

Received date: February 16, 2018; Accepted date: February 22, 2018; Published date: March 5, 2018

Copyright: (c) 2018 Giangaspero. This is an open-access article distributed under the terms of the Creative Commons Attribution License, which permits unrestricted use, distribution, and reproduction in any medium, provided the original author and source are credited.

\begin{abstract}
In Europe, since 2005, campylobacteriosis is considered among the most frequent cause of bacterial gastrointestinal infectious disease. The diffusion is cosmopolitan, accounting for an increasing global burden on public health, affecting primarily children under 4 years of age, causing gastroenteric symptoms, but also different extra intestinal pathologies. The infection appears associated also with malnutrition and growth impairment in disadvantaged communities. The consumption of contaminated poultry meat is considered to be the most frequent way of transmission. The progressive diffusion and increase of antibiotic-resistant Campylobacter strains is an issue, particularly in South America and Southeast Asia. Effective regulatory approaches are necessary at national and international level by both sanitary and veterinary authorities to counter such serious zoonosis, in the spirit of One Health.
\end{abstract}

Keywords: Campylobacter, Infectious disease; One health

\section{Introduction}

Campylobacteriosis is among the most diffuse infectious diseases of the last decades. The prevalence has particularly increased everywhere, independently from medicalization status, in both developed and developing countries. In regions of Africa, Asia, and the Middle East the infection is endemic in particular among infants. In Europe, since 2005, the infection due to thermotolerant Campylobacter spp. in humans become more frequent than that caused by Salmonella spp., representing the most common reported infectious gastrointestinal pathology [1]. According to the European Centre for Disease Prevention \& Control (ECDC) surveillance report of 2011, based on data from the European Surveillance System (TESSy), in Europe Campylobacter spp. infection was responsible for 178,000 cases in 2006 and accounted for up to 202,000 cases $(53.07$ per 100,000$)$ in 2009 . In 2012, the notified confirmed cases were 212,000. In Germany, Hungary and UK highest number of cases (up to 60,000) have been reported. Also in Switzerland, in 2009, campylobacteriosis resulted the most frequent bacterial zoonosis, with more than 8,000 reported cases (100.1 per 100,000) [2], inducing the establishment of the Campylobacter platform, an active monitoring plan at national level. Studies revealed particularly alarming estimations, as up to 500,000 cases per year in the United Kingdom [3]. Campylobacter jejuni and $C$. coli are the two species mainly isolated in man, especially during summer months. In 2009, C. jejuni was the most frequently reported species (36.4\%). The other species $C$. coli $(2.5 \%), C$. lari $(0.19 \%)$ and $C$. upsaliensis $(0.01 \%)$ were rarely isolated from patients. But many of the isolates from the other confirmed cases (51\%) could not be characterized. The health problem is cosmopolitan, for example, also in the United States campylobacteriosis in humans is one of the most common pathogens responsible for foodborne disease. According to data obtained through the active surveillance system ensured by the Foodborne Diseases Active Surveillance Network (FoodNet), every year, about 14 cases are diagnosed for each 100,000 persons in the population (6.033 notified cases in 2009). But the Centres for Disease Control and Prevention (CDC) estimated that the infection affects yearly more than 1.3 million patients, since many cases are supposed to go undiagnosed or unreported to public health authorities [4].

Campylobacteriosis is a zoonosis. Various domestic and wild animal species can host the bacterium and they act as natural reservoirs. The role of domestic avian species in the epidemiology of the disease in humans is well known. Domestic avian species are the main reservoir and source of transmission of Campylobacter spp. to man, often in relation with high levels of contamination in poultry meat $[5,6]$. Humans become infected through contact with animals and their products, such as avian meat and raw milk. The consumption of contaminated poultry meat not sufficiently cooked is considered to be the most frequent way of transmission. Often, contaminations are indirect occurring during manipulations of food for cooking in the in the kitchen environment, through stoves or other kitchen utensils utilized without precautions contemporaneously with raw meat and for other food.

The impact on public health is considered high, being associated with 7.5 million disability-adjusted life years according to the 2010 Global Burden of Disease Study, more than Shigella (7.1 million) and enterotoxigenic E. coli (6.9 million) [7]. On the base of fragmentary studies, the prevalence of $C$. jejuni and $C$. coli reported in relation with diarrhoea in human population from different countries, in South America showed rates ranging from $9.6 \%$ in Brazil and up to $41.3 \%$ among infants suffering from gastroenteritis in Peru [8,9] or $84.9 \%$ among infants of less than 6 months of age in Brazil and Peru [10].

In humans, symptoms are mainly gastroenteric. Few bacteria are sufficient to determine violent abdominal pain and diarrhoea. Both $C$. jejuni and C. coli may provoke enteritis in all age categories. But, most affected result to be infants under four years of age, as shown by epidemiological data reported in 2009 (144.34 per 100,000) [1]. In particular, $C$. jejuni can cause various extra intestinal forms. This includes bacteremia, meningitis, peritonitis, pancreatitis, cholecystitis, cystitis and urethritis, neonatal sepsis, abortion, endocarditis, osteomyelitis, septic thrombophlebitis, septic arthritis, as well as immunomediate chronic forms like nodous erythema. $C$. jejuni is also suspected in the etiopathogenesis of Guillain Barré the post infective 
Page 2 of 5

neurological syndrome and the rare variant Miller-Fisher syndrome. The similarity between bacterial lipopolysaccharides and gangliosides might be at the origin of an auto-immune reaction [11-13]. Furthermore, recent studies indicate an association between Campylobacter infection and malnutrition, caused by an induced intestinal and systemic chronic inflammation, with a subsequent perturbation of the growth, in low resourced communities, particularly evident also in Peru [10]. Nevertheless, the impact of $C$. jejuni, $C$. coli, and non-jejuni/coli Campylobacter strains in children, in particular living in the developing countries, constitute a threatening reality, even if greatly underestimated and largely undiagnosed. Among non-jejuni/ coli Campylobacter, there is an emerging recognition of the clinical importance of Campylobacter species as C. concisus and $C$. ureolyticus. Less frequently isolated in poultry, both species are suspected to be associated with Crohn's disease and ulcerative colitis in man [14-16]. The mortality rate associated with Campylobacter infection seems generally low ( 0.05 per 1,000 cases) [12]. It is not excluded that infection related mortality may also be higher and not negligible, as suggested by some studies. For example, mortality in relation to confirmed cases in the Netherlands, in 2008, accounted for 45 deaths out of 3,340 patients, and in 2010 deaths were 58 out of 4,322 cases [17].

Despite increasing importance for public heath, in veterinary medicine, monitoring of Campylobacter is often incomplete. In Switzerland, the $44 \%$ of poultry samples were positive mainly to $C$. jejuni. In pigs the $67 \%$ was positive, but with almost all for $C$. coli. Only the $1 \%$ of tested calves resulted positive to both $C$. jejuni and $C$. coli [2]. Campylobacter is often detected in poultry meat [6]. For example, high contamination percentages have been found in UK (71\%) [5] and Italy (81.3\%) [18]. In South America too, high contamination levels have been reported. In Brazil, $66.9 \%$ of live poultry and $68.8 \%$ of poultry meat resulted positives to $C$. jejuni $[19,20]$, while among cattle positive were $53.3 \%$ [21]. Reacting to the rising importance of campylobacteriosis, the European Commission financed a first monitoring program in the poultry sector to determine prevalence and levels of antibiotic resistance [22]. As in other countries, in Italy, this funding allowed to undertake extended epidemiological investigations, revealing high prevalence of Campylobacter in avian meat. The $72.3 \%$ of slaughter lots were positive, with percentages of positivity in carcasses up to $71.5 \%$ and $75.8 \%$ in Veneto and Marche regions, respectively [23]. The 52.1\% of characterized isolates were $C$. jejuni; $C$. coli represented the $55.6 \%$ and C. lari $1.1 \%$. Very high levels of contamination, e.g. $>10,000$ unit forming colonies (UFC)/g, have been also detected. Among wild animal species potential reservoirs of Campylobacter, avian families are most frequently infected, mainly crows (Corvidae) and gulls (Laridae) with the highest carriage rates of $C$. jejuni: $23 \%-89.8 \%$ and $25 \%-50 \%$, respectively $[24,25]$. In Italy were reported positive rates of $34.1 \%$ and $38.8 \%[26,27]$.

Animals are generally, asymptomatic carriers of Campylobacter spp.. However, in wild animals, occurrence of gastroenteritis related with Campylobacter was described in different animal orders: Artiodactyla 15\%, Galliformes 15\%, Anseriformes 30\%, Ciconiformes $34 \%$ and Gruiformes $44 \%$ [28]. In addition, $C$. jejuni was reported to be associated with pathologies affecting various species such as mink (Mustela vison) suffering from colitis, severe diarrhea, abortion and death, or severe diarrhea in in primates and raccoon (Procyon lotor), and enteritis and hepatitis in ostrich (Struthio camelus).
Currently, the prevention of campylobacteriosis relies mainly on general hygienic approaches. Preventive measures in food safety have to be applied at all the levels of the food chain from primary production up to distribution retail, and not neglecting good hygienic practices at household, recognized also relevant aspects. The World Health Organization (WHO) has developed policies for the promotion and strengthening of food safety systems, good practices in the manufacturing sector as well as education of food business operators and consumers on appropriate food handling in order to avoid cross contamination. Risk communication, through education of consumers and training of food handlers is among the most critical interventions to prevention foodborne illnesses [29]. To reduce the prevalence of Campylobacter in poultry, it is necessary to enhance biosecurity measures at farm level to avoid introduction of Campylobacter from the environment. Similarly, safe disposal of faeces and articles soiled with faeces is particularly important in countries without adequate sewage disposal systems. This requires closed housing conditions, despite preferable free ranging farming for animal welfare. The application of good hygienic practices during slaughtering will ensure the reduction of the contamination of carcasses by faeces, but they will not guarantee the complete elimination of Campylobacter, thus, meat and meat products will maintain a certain risk level. Few methods, such as heating (e.g. cooking or pasteurization) or irradiation, are effective to eliminate Campylobacter in contaminated foods [29]. In low resource settings, the reduction of the burden of Campylobacter infection for the improvement of growth in children can be achieved through the promotion of breastfeeding, avoiding the use of potentially contaminated water for the preparation of maternal milk substitution, adequate treatment of drinking water, improved hygiene of latrines, and targeted antibiotic treatment, avoiding the use of known antibacterials with demonstrated resistance among Campylobacter strains [10].

The high level of contamination of food of animal origin is the primary issue. It has been estimated that the reduction of the $90 \%$ of the cases of human campylobacteriosis could be achieved by limiting contamination levels under 500 UFC per gram in raw poultry meat [2]. Therefore, it should be a priority objective to reduce the bacterial burden of raw meat to radically decrease the impact of the infection on public health. To date, vaccination of chickens against Campylobacter is still at experimental level, but with preliminary promising results [30]. Pathogen reduction treatments (PRTs), such as physical treatments with temperature or pression or chemical compounds as chlorate solutions, can efficiently reduce the burden of pathogens from the surface of the meat when applied on poultry carcasses at the end of the slaughtering process $[31,32]$. But, only the use of lactic acid as PRT in plants processing bovine meat has been recently authorized by the European Union (EU) [33]. All other practices are not permitted according to the enforced European food law [34]. Such legal diverging framework caused long term disputes between EU and USA sanitary veterinary administrations [35]. It will be therefore interesting to drive research efforts focused on alternative means for the achievement of the objective to reduce contamination levels, and taking into account that application of current hygienic measures during slaughtering and subsequent evisceration does not effectively prevent contamination of meat surface from bacteria present in the intestinal contain.

Of particular importance, it is the increasing number of reports on Campylobacter strains resistant to different antibiotics, not only in Europe [36,37], but also and especially in Southeast Asia and South America. After the substantial increasing of resistance to quinolones and fluoroquinolones during the last decade [38], resistance to 
Page 3 of 5

macrolides has been more and more described, as Azithromycin in India and Peru [39,40]. In Latin America, various studies demonstrated the circulation of particularly high number of isolates of resistant Campylobacter spp.. In Brazil, up to $72.2 \%$ of isolates were resistant to quinolones, up to $43 \%$ to tetracycline, or up to $38.9 \%$ to erythromycin and up to $26.9 \%$ for ampicillin [41-43]. Very high percentages $(47-78 \%)$ of strains resistant to quinolones have been described also in Argentina, Bolivia, Chili and Peru; as well as from $40.8 \%$ to $65.9 \%$ for tetracycline in Argentina and in Bolivia; from $58.6 \%$ to $61.4 \%$ for erythromycin in Bolivia and Chili, or $47.2 \%$ for ampicilline in Argentina [44-49]. These observations indicate the generality of the problematic also in this continent. In particular, this phenomenon highlights the high risk of the direct relation between resistance of strains isolated in man and utilisation of these molecules in veterinary medicine in particular in the poultry sector, and this even after years since the enforcement of the ban in EU and USA of the non-therapeutic use of antimicrobials in domestic animals, as enrofloxacin in poultry farms [50,51]. Love and collaborators [50] demonstrated high percentages of inhibitory levels of forbidden quinolones in poultry feathers, with the risk of their reintroduction in the food chain through fertilization or animal feeding. This suggests that the ban as now applied does not seems to prevent exposure of poultry to the molecules known to induce antibiotic resistant Campylobacter. In addition, the use of antimicrobials as fluoroquinolone, for prophylaxis or growth promotion in farmed animals, is still permitted in many developing countries, and cheaper generics can increase these practices.

Campylobacteriosis is relevant for the "One Health" concept, based on the idea that human health and animal health are interdependent. This concept, introduced at the beginning of the 2000s, was envisaged and implemented by the World Organization for Animal Health (Office International des Épizooties: OIE) as a collaborative global approach to understanding risks for human and animal health. However, in veterinary medicine, legal norms formulated for Campylobacter spp. are probably insufficient and enforcement in the field appears problematic. Generally, animals are asymptomatic carriers of Campylobacter spp., the silent infection is widespread and endemic in the zootechnic sector, and this may explain the apparent low reactivity against the infection by the farmers, probably also related with inadequate risk communication. Practically, no obligation of declaration or restriction to distribution and commercialization of affected live animals and contaminated food of animal origin are implemented.

Campylobacteriosis has been included among diseases submitted to rules for the prevention and control in Annex II of the EU Regulation 429 [52]. However, at international level it is compulsorily reportable only for bovine genital campylobacteriosis [53], while not contemplated among diseases of avian species, thus, not relevant for international trade rules of animals and animal products according to World Trade Organization's Sanitary and Phytosanitary agreements (WTO SPSS). For example, when compared to other zoonotic pathogens circulating in Europe or exotic, such as C. burnetii (Q fever) or Nipah virus (NiV), Campylobacter appears to be much less important to the $\mathrm{NiV}$, most dangerous agent (Table 1).

In fact, due to the significant morbidity and mortality, and rapid spread potential in domestic animals, and evidence of zoonotic properties, recently, Nipah virus has been included in the list of diseases with relevance for international trade of the World Organization for Animal Health (OIE) [53]. In NiV non-endemic countries scientific attention is high on henipaviruses, and practical regulatory field implications foreseen that $\mathrm{NiV}$ outbreaks have to be immediately notified to OIE by the veterinary authority. In contrast, despite the recognized importance taking into account the very high incidence in human population, inclusion of Campylobacter in national veterinary monitoring plans remains questionable and prioritization may drive the attention to other pathogens showing for example higher health impact in the animal population.

\begin{tabular}{|l|l|l|l|}
\hline Pathogen & Campylobacter spp. & C. burnetii & Nipah Virus \\
\hline $\begin{array}{l}\text { OIE notifiable } \\
\text { disease }\end{array}$ & $\begin{array}{l}\text { Multiple } \\
\text { Bovine diseases genital } \\
\text { campylobacteriosis } \\
\text { species } \\
\text { diseases } \\
\text { Fever }\end{array}$ & $\begin{array}{l}\text { Pig diseases } \\
\text { Nipah virus } \\
\text { encephalitis }\end{array}$ \\
\hline $\begin{array}{l}\text { Zoonosis } \\
\text { YES }\end{array}$ & YES & YES \\
\hline $\begin{array}{l}\text { Pathogenicity in } \\
\text { man }\end{array}$ & + & + & +++ \\
\hline $\begin{array}{l}\text { Therapeutic or } \\
\text { prophylactic means }\end{array}$ & YES & YES & NO \\
\hline Risk Category & 2 & 2 & 4 \\
\hline Domestic animals & YES & YES & YES \\
\hline Wild animals & YES & YES & YES \\
\hline
\end{tabular}

Table 1: Comparison between Campylobacter spp. and other zoonotic pathogens. NiV appears to be the most dangerous agent. Risk category classification according to the Italian National Committee for biosafety and biotechnology and life sciences [54].

\section{Conclusion}

In conclusion, knowledge and awareness on the disease should be harmonized, improved and disseminated among health services, veterinarians, farmers and consumers. Taking into account that Campylobacter is considered to be the most common cause of bacterial gastroenteritis worldwide, this One Health issue will need to be dealt with on an international scale, trough harmonized sanitary and veterinary regulatory measures.

\section{References}

1. European Center for Disease Prevention \& Control (ECDC) (2011) Annual epidemiological report. Reporting on 2009 surveillance data and 2010 epidemic intelligence data.

2. Office fédéral de la Sanité Publique (2010) Rapport suisse sur les zoonoses 2010.

3. Tam CC, Rodrigues LC, Viviani L, Dodds JP, Evans MR, et al. (2012) Longitudinal study of infectious intestinal disease in the UK (IID2 study): incidence in the community and presenting to general practice. Gut 61: 69-77.

4. Centers for Disease Control and Prevention (CDC) (2013) Campylobacter general information.

5. Meldrum RJ, Tucker D, Edwards C (2004) Baseline rates of Campylobacter and Salmonella in raw chicken in Wales, United Kingdom, in 2002. J Food Prot 67: 1226-1228.

6. Suzuki H, Yamamoto S (2009) Campylobacter contamination in retail poultry meats and by-products in the world: a literature survey. J Veterinary Medical Science 71: 255-261.

7. Murray CJ, Vos T, Lozano R, Naghavi M, Flaxman AD, et al. (2012) Disability-adjusted life years (DALYs) for 291 diseases and injuries in 21 
Page 4 of 5

regions, 1990-2010: a systematic analysis for the Global Burden of Disease Study 2010. Lancet 380: 2197-2223.

8. Fernández H (2011) Campylobacter and campylobacteriosis: a view from South America. Rev Peru Med Exp Salud Publica 28: 121-127.

9. Platts-Mills JA, Liu J, Gratz J, Mduma E, Amour C, et al. (2014) Detection of Campylobacter in stool and determination of significance by culture, enzyme immunoassay, and PCR in developing countries. J Clin Microbiol 52: $1074-1080$.

10. Amour C, Gratz J, Mduma E, Svensen E, Rogawski ET, et al. (2016) Epidemiology and impact of campylobacter infection in children in 8 low-resource settings: results from the MAL-ED study. Clin Infect Dis 63: 1171-1179.

11. Allos BM (2001) Campylobacter jejuni Infections: Update on Emerging Issues and Trends. Clin Infect Dis 32: 1201-1206.

12. Center for Food Security and Public Health (CFSPH) (2005) Campylobacteriosis.

13. Requena L, Requena C (2002) Erythema nodosum. Dermatol. Online J 8: 4.

14. Mahendran V, Riordan SM, Grimm MC, Tran TAT, Major J, et al. (2011) Prevalence of Campylobacter Species in Adult Crohn's Disease and the Preferential Colonization Sites of Campylobacter Species in the Human Intestine. PLOS ONE 6: e25417.

15. O'Donovan D, Corcoran GD, Lucey B, Sleator RD (2014) Campylobacter ureolyticus A portrait of the pathogen. Virulence 5: 498-506.

16. Zhang L, Man SM, Day AS, Leach ST, Lemberg DA, et al. (2009) Detection and Isolation of Campylobacter Species Other than C. jejuni from Children with Crohn's Disease. J Clin Microbiol 47: 453-455.

17. World Organisation for Animal Health - Office International des Épizooties (OIE) (2013) Country information, Zoonoses. World Animal Health Information System.

18. Pezzotti G, Serafin A, Luzzi I, Mioni R, Milan M, et al. (2003) Occurrence and resistance to antibiotics of Campylobacter jejuni and Campylobacter coli in animals and meat in northeastern Italy. Int J Food Microbiol 82: 281-287.

19. Fernandez H (1983) Espécies termófilas de Campylobacter: Aspectos bacteriológicos, epidemiológicos e patogênicos. Thesis, São Paulo: Mestrado em Microbiologia e Imunologia. Escola Paulista de Medicina.

20. Kuana SL, dos Santos LR, Rodrigues LB, Borsoi A, Moraes HLDS, et al. (2008) Antimicrobial resistance in Campylobacter spp isolated from broiler flocks. Braz J Microbiol 39: 738-740.

21. Modolo JR, Biping W, Kirpal K (1988) Biochemical characters of Campylobacter sp. isolated from calves with and without diarrhea. Rev Microbiol 19: 1-5.

22. European Union (2007) Commission Decision 2007/516/EC of 19 July 2007 concerning a financial contribution from the Community towards a survey on the prevalence and antimicrobial resistance of Campylobacter spp. in broiler flocks and on the prevalence of Campylobacter spp. and Salmonella spp. in broiler carcasses to be carried out in the Member States.

23. Di Giannatale E, Prencipe V, Colangeli P, Alessiani A, Barco L, et al. (2010) Prevalence of thermotolerant Campylobacter in broiler flocks and broiler carcasses in Italy. Vet Ital 46: 405-423.

24. Kapperud G, Rosef O (1983) Avian wildlife reservoir of Campylobacter fetus subsp. jejuni, Yersinia spp., and Salmonella spp. in Norway. Appl Environ Microbiol 45: 375-380.

25. Keller JI, Shriver WG, Waldenström J, Griekspoor P, Olsen B (2011) Prevalence of Campylobacter in wild birds of the mid-Atlantic region, USA. J Wildl Dis 47: 750-754.

26. Levrè E, Valentini P, Brunetti M, Sacchelli F (1989) Stationary and migratory avifauna as reservoirs of Salmonella, Yersinia and Campylobacter. Ann Ig 1: 729-740.

27. Robino P, Tomassone L, Tramuta C, Rodo M, Giammarino M, et al. (2010) Prevalence of Campylobacter jejuni, Campylobacter coli and enteric Helicobacter in domestic and free living birds in North-Western Italy. Schweiz Arch Tierheilkd 152: 425-431.
28. Taema MM, Bull JC, Macgregor SK, Flach EJ, Boardman WS, et al. (2008) Retrospective Study of Campylobacter Infection in a Zoological Collection. Appl Environ Microbiol 74: 1332-1338.

29. http://www.who.int/mediacentre/factsheets/fs255/en/

30. Annamalai T, Pina-Mimbela R, Kumar A, Binjawadagi B, Liu Z, et al. (2013) Evaluation of nanoparticleencapsulated outer membrane proteins for the control of Campylobacter jejuni colonization in chickens. Poult Sci 92: 2201-2211.

31. Boysen L, Rosenquist H (2009) Reduction of thermotolerant Campylobacter species on broiler carcasses following physical decontamination at slaughter. J Food Prot 72: 497-502.

32. Misawa N, Shinki T, Sasaki S (2011) Development of an effective decontamination of Campylobacter species on chicken carcasses. Proceedings of the 16th International Workshop on Campylobacter, Helicobacter, and related organisms. August 28-September 1 2001, Vancouver, Canada.

33. http://eur-lex.europa.eu/legal-content/EN/ALL/?uri=CELEX \%3A32013R0101

34. http://eur-lex.europa.eu/LexUriServ/LexUriServ.do?uri=OJ:L: 2004:139:0055:0205:en:PDF

35. Johnson R (2015) U.S.-EU Poultry Dispute on the Use of Pathogen Reduction Treatments (PRTs). Congressional Research Service.

36. Châtre P, Haenni M, Meunier D, Botrel MA, Calavas D, et al. (2010) Prevalence and antimicrobial resistance of Campylobacter jejuni and Campylobacter coli isolated from cattle between 2002 and 2006 in France. J Food Prot 73: 825-831.

37. Wieczorek K, Kania I, Osek J (2013) Prevalence and antimicrobial resistance of Campylobacter spp. isolated from poultry carcasses in Poland. J Food Prot 76: 1451-1455.

38. Mukherjee P, Ramamurthy $\mathrm{T}$, Bhattacharya MK, Rajendran K, Mukhopadhyay AK (2013) Campylobacter jejuni in hospitalized patients with diarrhea, Kolkata, India. Emerg Infect Dis 19: 1155-1156.

39. Pollett S, Rocha C, Zerpa R, Patiño L, Valencia A, et al. (2012) Campylobacter antimicrobial resistance in Peru: a ten-year observational study. BMC Infect Dis 12: 193.

40. Mukherjee P, Ramamurthy T, Mitra U, Mukhopadhyay AK (2014) Emergence of high-level azithromycin resistance in Campylobacter jejuni isolated from Paediatric Diarrhoea cases in Kolkata, India. Antimicrob Agents Chemother 58: 7 .

41. Miranda KL, Lage AP (2007) Antimicrobial susceptibility of Campylobacter sp strains isolated from calves with and without diarrhea in Minas Gerais state, Brazil. Braz J Microbiol 38: 357-362.

42. Kuana SL, Santos LR, Rodrigues LB, Borsoi A, Moraes HL, et al. (2008) Occurrence and Characterization of Campylobacter in the Brazilian Production and Processing of Broilers. Avian Dis 52: 680-684.

43. Lopes GV (2009) Campylobacter spp. in slaughter and retail: occurrence in bovine carcasses for export and in refrigerated cuts of poultry and cattle. São Paulo.

44. Figueroa G, Troncoso M, Galeno H, Soto V, Toledo MS (1990) Biotypes, serogroups and antibiotic susceptibility of Campylobacter jejuni and Campylobacter coli in Chile. J Infect 20: 123-127.

45. Fernández H, Mansilla M, González V (2000) Antimicrobial susceptibility of Campylobacter jejuni subsp. jejuni assessed by E-test and double dilution agar method in Southern Chile. Mem Inst Oswaldo Cruz 95: 247-249.

46. Modolo JR, Giuffrida R, Lopes CAM (2003) Antimicrobial susceptibility of 51 Campylobacter strains isolated from diarrheic and diarrhea-free dogs. Arq Inst Biol 70: 283-286.

47. Pantozzi FL, Moredo FA, Vigo GB, Giacoboni GI (2010) Resistance to antimicrobials in indicator and zoonotic bacteria isolated from domestic animals in Argentina. Rev Argent Microbiol 42: 49-52.

48. Olaguibel OL (2009) Monitoreo de la resistencia antimicrobiana de Campylobacter spp. en cuatro hospitales de la ciudad de La Paz-Bolivia. Thesis. La Paz: Facultad de Ciencias Farmacéuticas y Bioquímicas, Universidad Mayor de San Andrés. 
Citation: Giangaspero M (2018) A Cosmopolitan One Health Issue: Campylobacteriosis. Clin Microbiol 7: 308. doi:10.4172/2327-5073.1000308

Page 5 of 5

49. Ministerio de Salud, Dirección General de Salud de las Personas, Perú (2001) Estudio de etiología de la diarrea en las direcciones de salud Cajamarca, Lambayeque, Loreto y Lima este. Informe Técnico, Lima MINSA 21.

50. Love DC, Halden RU, Davis MF, Nachman KE (2012) Feather meal: a previously unrecognized route for reentry into the food supply of multiple pharmaceuticals and personal care products (PPCPs). Environ Sci Technol 46: 3795-3802.
51. United States Food and Drug Administration. (2011) Retail meat report: national antimicrobial resistance monitoring system. UCM334834.

52. http://eur-lex.europa.eu/legal-content/EN/TXT/?uri=CELEX \%3A32016R0429

53. World Organisation for Animal Health (Office International des Épizooties: OIE) (2017) OIE listed diseases 2017.

54. http://presidenza.governo.it/biotecnologie/documenti/ documento_composto.pdf 